\title{
Circumstantial Indications Emitted by the Teacher during Discursive Activity
} -An Application in an Experimental Physics Class

\author{
Carlos Eduardo Laburú1, Osmar Henrique Moura da Silva1, Marcelo Alves Barros², \\ Andreia de Freitas Zômpero ${ }^{3}$ \\ ${ }^{1}$ Physics Department, Londrina State University, Londrina, PR, Brazil \\ ${ }^{2}$ Physics Institute of São Carlos, University of São Paulo, São Carlos, SP, Brazil \\ ${ }^{3}$ University of North Paraná, Londrina, PR, Brazil \\ Email:`laburu@uel.br, osmarh@uel.br, mbarros@ifsc.usp.br, andzomp@yahoo.com.br
}

How to cite this paper: Laburú, C. E., da Silva, O. H. M., Barros, M. A., \& de Freitas Zômpero, A. (2017). Circumstantial Indications Emitted by the Teacher during Discursive Activity-An Application in an Experimental Physics Class. Creative Education, 8, 1339-1356.

https://doi.org/10.4236/ce.2017.88095

Received: May 30, 2017

Accepted: July 23, 2017

Published: July 26, 2017

Copyright $\odot 2017$ by authors and Scientific Research Publishing Inc. This work is licensed under the Creative Commons Attribution International License (CC BY 4.0).

http://creativecommons.org/licenses/by/4.0/

\begin{abstract}
This study makes use of a reading of Prieto's semiotics with the aim of shedding light on semiotic elements that occur during the discursive process in the classroom. Taking as reference an overview of this author's theories in the context of science education, the paper focuses on the semiotic element of circumstantial indications. Circumstantial indications are a collateral and not always explicit type of sign in the teacher's communication that assist the meaning of messages conveyed by signals. Compared with indications, signals are signs transmitted explicitly and openly that constitute the main axis of the discourse. In the course of classroom communication, teachers emit circumstantial indications in parallel with the transmitted signals. The signals refine the understanding of the messages of the scientific concepts being taught in order to make them more meaningful. This study investigates one Physics teacher's class in a lab in which an empirical activity is guided at various moments through discursive activity based on problem-solving methodology. The paper identifies and qualifies some types of circumstantial indications emitted by the teacher, contextualizing their role in the discursive process during teaching.
\end{abstract}

\section{Keywords}

Teaching, Semiotics, Signals, Circumstantial Indications, Discourse

\section{Introduction}

The extensive and influential tradition of research about the model of conceptual change in the eighties and nineties (Duit, 2003) set itself the challenge of con- 
fronting the preconceptions of learners and supplanting them with scientific concepts. However, its theoretical elaborations directed to this end were limited when trying to promote significant improvements in this direction (Hubber et al., 2010: p. 5). Later works have both questioned and supplemented the exclusively conceptual orientation of learning in this research field. Regarding the latter, research in science and mathematics education has begun to use semiotic studies in order to shed light, for example, on the question of the various discourses and their representations in teaching (Lemke, 2003; Prain \& Waldrp, 2006; Laburú \& Silva, 2011), on the cognitive and expressive role of signs in the form of gestures (Roth, 2001; Radford, 2009), or appropriating Peirce's theory to establish analytical guidelines for teaching and learning (Manechine \& Caldeira, 2010; Almeida, Pessoa da Silva, \& Vertuan, 2011; Wartha \& Rezende, 2011).

A key object of interest in semiotic studies concerns the noesis and semiosis relationship, that is, the formation and acquisition of concepts that are processed alongside signic production and emission, respectively (Duval, 2004: p. 14). Merely skimming the general nature of this cognitive theme, this work is more concerned with the signs transmitted during the communication of scientific discourse by the teacher. In particular, the signs dealt with here are those that act in a collateral and indirect manner in the narrative, but which present a contextual and complementary role, supporting and enhancing the understanding of the subject narrated. For the sake of clarity, the gestures and body language alluded to (Kendon, 2005) are examples of signs that often take on this role.

While such types of signs are able to assist learning, given their supplementary and circumstantial place in the discourse (op. cit., p. 1), it is not difficult to imagine that they can, like any other sign, lead the learner to misconceptions that are often erroneously identified with issues of content directly taught such as facts, ideas, terminology, specific procedures, and so on. Of course, the latter are mainly trivial cases of misunderstandings, since they are easily spotted and corrected. However, many deep and incorrect understandings appear from underlying educational rules that exist in the classroom (Edwards \& Mercer, 1993: p. 60 ) or resulting from the misinterpretation of signals emitted subliminally and adjacent to the main discourse conveyed by the teachers.

Given what has been stated, and as will become clearer in the presentation of this work, we propose to investigate possible signs, called circumstantial indications, that the teacher makes when delivering the message of the scientific narrative being taught. During their classes it is common for teachers to emit, whether in a programmed manner or not, signs of a circumstantial nature that has the role of contextualizing and complementing the message. The contextualizing aspects of circumstantial indications enable a better understanding of the concepts of the narrative. Therefore, identifying and characterizing possible signs of the circumstantial indication kind arising in the instructional process is a relevant issue that occurs in the context of learning. Studying these indications may help us recognize students' misconceptions, and, more especially, to recognize that they may constitute important elements of stimulation of the learner's ref- 
lective process when planned by the teacher to act in this way.

Before continuing the exposition that will give a clearer understanding of the problematic posed, two prior clarifications are required. First, in the light of the different nuances of the theoretical objects and ideological assumptions of many semioticians to be presented, we risk confusing those that rigorously preserve the terminology of each theoretician. The most important commitment of this work lies in the transposition of the theoretical framework of their theories of signs to scientific education. Subsequently, we allow ourselves to expand and extrapolate new interpretations of the concepts, taking into account the induction of productive and consistent instructional implications. Consequently, the pursuit of possible improvements in teaching and learning mechanisms or in discourses and approaches alternative to those that exist in the literature, is given far more importance than any differences. Additionally, theoretical assumptions on the surface, might lead to tensions between authors or fidelity to their ideas. Thus, a free reading will be present every time these concerns demonstrate relative relevance for such purposes. Therefore, we are aware that the gain with the transposition into science education corresponds to inevitable losses with regard to a greater theoretical austerity when the concepts of the various semiotic experts are invoked and juxtaposed, in addition to the fact that they are focused on another area of expertise.

The second clarification concerns the terms emitter and receiver to be used in the light of communication theory. Contrary to what it might seem at first glance, they are far from being identified with a traditional objectivist teaching style based on the exclusivity of information transmission (Davis, 1993). The way the language is used may at times lead in a misleading way to that understanding, the active role of the learner and the mediation of the teacher in the construction of the students' knowledge are, on the contrary, explicit in educational activities conducted both through the discursive process and the methodology of problems specified. The learner, therefore, is far from being qualified as a passive being, as an objectivist education advocates (op. cit.). Therefore, the use and choice of the referent semiotics language has, first of all, to offer a support that is logical and molded to understanding the cognitive improvement of the learner. Secondly it notes consequent actions of the teacher in the classroom, in order to inspire educational activities with greater significance, without a loss of identification of the original theoretical sources behind this endeavor.

The discussions below are structured as follows. In the theoretical section, the general semiotic frameworks that support the work are located and developed, leaving a subsection to the central theme of the article that relates the need to contextualize the message of a signal and the function of the circumstantial indication sign in that process. Then, a section discusses the research object and situates its problematic. From this, the sections of the methodology used and the data analysis are presented. In the final section we close the article presenting the conclusions. 


\section{Theoretical Foundation}

To satisfy certain requirements of social life, the members of a human group need to transmit messages to each other. To do so, they must perceive, distinguish, select and relate classes of messages and their associated signals. However, the direct experiences of each individual with respect to the same object or signal can differ significantly from the situation. Despite this, the curious thing is that individuals may share similar understandings of the same experience or message. This happens even though there are no two behaviors or two identical states of consciousness. Even so, speakers are able to recognize states of consciousness one from the other by means of signs that transmit messages. By signs, we wish to refer to recognizable signal-based entities that make up a class of operations that can be performed and that are intended to make known a state of consciousness (Prieto, 1973: p. 10).

A person who wants to communicate a state of consciousness only has available a culturally predetermined set of abstract signs to constitute the message and which should, at the end of this, lead to a behavior. Recognition of the significance of the message, by the person for whom the communication is intended, takes place via abstraction of its functional elements. In general, individuals can decide what the other person means by a particular sign, and are able to understand the degree to which two meanings are identical or different. In turn, they can affect the behavior with the performance expected by the agent of the interlocution. This occurs when similar relationships of meaning are maintained, for both the one and the other, thus permitting a sign to acquire shared understanding. However, when the relationships in question differ, the meaning of the sign for each individual also differs. Since the relationships mentioned above may present different natures, with regard to their composition, their hierarchy or their connections etc., in practice the determination of meanings is difficult. Additionally, the differences in the use of signs by people even from the same social group can be quite large. Hence, the reason flaws in the reconstitution of the state of consciousness of whoever communicates it and makes it similar to that of the recipient.

Buyssens (1974) claims, in other terms, that the communication process involves knowing how to abstract and concretize meanings. However, for a person who receives the communication, such a process is never perfect because meaning is conventional, establishing itself by discovery, by approximation to what it has in common with the acts of consciousness of those who communicate. Hence, the reason why the conventional character of every sign transmitted in a discursive composition is incomplete, including, at any time, the opportunity existing to complete its significance by resorting to other signs of the same representational nature or through different representations (Lemke, 2003; Prain \& Waldrip, 2006).

In addition, since our relationship with the world is not direct, but mediated by signs as Vygotsky says, the development of higher mental functions (e.g., voluntary attention, logical memory, verbal and conceptual thought) is processed 
by the internalization of systems of signs produced culturally (Freitas, 1995). For Vygotsky, the signs fulfill a cognitive role to the extent that they function as a support for memory and a powerful instrument of language mediation, developing thinking and expanding our capacity for action on the world (Oliveira, 1993). Without the possibility of characteristic and permanent exterior signs, in support of memory, a substitute of own individual representations that are harder to distinguish and handle, there would be no higher spiritual life, not to mention science (Husserl apud Fidalgo, 1998: p. 45). Kubli (2005: p. 504) says that individual consciousness is nurtured through signs, with its growth being derived from them. For Peirce (apud. Eco, 2003: p. 146), every time we think we have present in our consciousness some feeling, image, design or other representation that serves as a sign. According to him, man can only think in words or other external signs. And since "every thought is a sign, then man is a sign". Through this metaphor the author highlights the vital importance of the sign for the characterization of the person and complements its position. He further states "both man and words or other external symbols educate each other reciprocally, since each enrichment of human information involves-and is surrounded by-a corresponding enrichment of word information" (Eco, 1985: p. 146).

In more synthetic terms, the human and the symbolic cannot be separated, and as Kubli (2005: p. 507) noted, meaning itself is inseparable from the realm of signs exchanged between members of a community, not being restricted to an individual mind. Vygotsky (2003) adds an important complementary element in these ideas when he recalls the mediating role of the other more "expert" in the process of appropriation of meaning during the construction of new knowledge by an individual less "expert" in that knowledge. Thus, it is up to the "expert" to assist in moving from the actual level of development to the level of proximal development of the individual. It is important to say that this author recognizes the fundamental relationship between giving meaning to the students' previous knowledge and knowledge (Putney, 2007). In this case, this relation participates both on the side of the signal, on the aspect of sense, as on the circumstances, or rather, on the circumstantial indication, in the aspect of previous knowledge.

It is worth clarifying that the notion of semiotic representation addressed here goes beyond the nature of a full language such as words, designs, diagrams, photos etc. It can also express a mere gesture to run to catch up with someone, any physical event, a situation, an object shown, a simple emotion or any feeling connected to the vague quality of feeling tenderness, desire, anger, pain, among others. Therefore, when emotions, actions, reactions, among other experiences are externalized, they embody the thoughts (Santaella, 2005: p. 10), producing meanings, therefore also presenting semiotic nature.

As mentioned, to cope with social life, people need to transmit messages to each other through signs. They must also be able to distinguish classes of messages and signals, in addition to establishing correspondence between the two, otherwise they will not achieve the purpose that they intended. The subjects 
must be in agreement as to the classes to distinguish and the correspondence to be established between them. Prieto (1973) states that everything that is in the universe and is of significance to human beings passed through the meaning of signs and was ordered by them. When sign-function exists, that is, when a code associates an expression with content, the signals are considered signs. Deprived of such a function, a sign does not mean anything; it is a mere stimulus (Eco, 2003: p. 15). By relying on the meaning of signs, human beings conceive the outside world and this makes it possible to transmit messages (meanings), exerting influence on other members of the social group. In the process of conveying a message, the sender of a signal establishes one of the social relations of "information", "interrogation" or "order", causing what is called a semic act (Prieto, 1973: p. 15).

\section{Communication and circumstances}

We cannot think of understanding signs without seeing them in some way characterized by their own contextual destinations. This is the way one can explain why someone succeeds in appropriating a certain linguistic act. In the light of this, the pragmatist philosophical current initiated by Peirce paid special attention to the relationship between signs and their users. His pragmatism understands that beyond the syntactic and semantic dimensions in the analysis of the sign process exist a cyclical dimension, i.e., the sign does not exist independently of the context of its use. This means that the meaning of signifying forms passes through syntactic analysis, through the consideration of semantic values and through the induction of the conditions and situations of its use (Fidalgo \& Gradim, 2005: p. 99). Then, common to all communication is a double, interdependent and inherent aspect that should be considered: it has no complete significance on its own and neither does it occur in isolation, but remains dependent on various sources of information and a contextual domain of social experiences and meanings (Jaipal, 2010: p. 52). Thus, a specific message that the sender tries to convey needs to be favored among other various and different messages, which can be possible through the indication of a signal and the circumstances that direct the receiver's attention (Prieto, 1973: p. 19). Prieto defines circumstances as any act that should be recognized by the receiver at the time of occurrence of any semic act.

Furthermore, this fact belongs to a context previously known by him prior to the emission of the signal of a semic act and specifies the message of the signal within several possible messages that carry the same sign. In other words, the indication arising from the signal is insufficient for the receiver to assign a particular message, because the number of different messages admitted by a sign is practically endless. Thus, the indication provided by the circumstance, known as circumstantial indication, favors the messages admitted by the signal differently. Further, it enables the receiver to determine that the message the sender transmits is, among all messages admitted by the signal, the one that the circumstances most favor (Prieto, 1973: p. 18). A teaching example to illustrate what is meant would be use of the same signal attached to the words "sense" or "force" 
leading to different messages, depending on whether the conceptual field referred to Physics or to everyday life. The context of each emission of each word determines the specific messages of their signals. Therefore, the receiver can select a given message from the signal because this is always produced in specific circumstances already known by the receiver at the time of the semic act, and which provides supplementary indication independent of that act.

As can be seen, all communication makes assumptions about what the recipient should know, taking them as a basis for further interpretation. Grize (op. cit Duval, 2004: p. 91) states that there can be no discourse the development of which does not take into account the real or supposed representations of their present or virtual recipient. Thus, the message receiver is continually anticipating the expressions of another, filling in empty spaces in utterances, texts and tasks, predicting or assuming words what the speaker will say or should not have said or may never even say (Eco, 2003: p. 124). Simple propositions admit more than one sense, because the status that determines their place in the discursive organization of a set of propositions, or the role they play in the discursive expansion, depends on the context of enunciation (Duval, 2004: p. 97).

Therefore, whoever performs an interpretation of a communication takes a different path to the meaning (Lemke, 2003). Individuals do not interpret a text in a similar way because they start from different initial conditions of knowledge, experiences and perspectives. Evidently, the effect on a subject due to a sign, this being understood in its broad sense of a concept or even a scientific theory, depends on the history of the individual, responsible for generating an interpretation. A given idiosyncratic interpretation has to do with the context that affected the person in the past and it becomes, thereafter, a recurring experience for him (Ogdan \& Richards, 1989: p. 55). So, any interpretation is part of a certain type of psychological context through which the individual passes or has passed. A context is constituted by a set of mental events, which can be tremendously numerous, accidental and separated in time. Thanks to this temporal separation, connections with new contexts can be made, with new recurrences and partial uniformities emerging, allowing creative predictions, inferences, acknowledgments, inductive generalizations, knowledge or opinions (ibid., p. 56). It may be concluded from these ideas that communication is a complex undertaking. In addition to indications emitted by signals, complementary circumstantial indications that both the emitter and the recipient need to know, about more or less encoded events and entities. The semantic assumptions of such events participate in the meaning of the expression, often find themselves implicit and analytically included, but which require the recipient to recognize them.

Prieto (1973: p. 20) states that the essential precondition for verifying an indication is that there is some uncertainty as to a fact in relation to others. On account of the various possibilities among which it is not known which is effectively carried out, to reduce this uncertainty. The index aims to dispel uncertainty totally or partially since "it always indicates a class of possibilities, to which belongs the possibility that is effectively carried out and which is consti- 
tuted among those possibilities that the index does not eliminate" (ibid. p. 22). Prieto gives an example, saying that the relatively large size of traces of animal tracks with a horseshoe shape indicates that the possibility that is effectively carried out belongs to the class of horses and not to any other animal or equine beast. Thus, the class of the possibilities effectively carried out is logically opposed to the class of possibilities that is not effectively carried out. The set of both possibilities at stake in the indicating plane is called the universe of discourse. The index as a member of this universe acts in a non-isolated manner to provide an indication (ibid., p. 24, 28).

In short, the receiver of a semic act is obliged to know the purpose of the sender when the latter transmits a particular message. This purpose is identified in the information provided by both the production of the main signal and the circumstantial collateral indications that accompany this production. And in order for the semic act to be successful, which means to say that a "good understanding" exists, the message that the sender intends to transmit and the message that the receiver attributes to the signal should be one and the same message.

However, what is to be expected when a semic act fails, that is, when the message transmitted and the message received do not match? This situation is characterized as a failure of understanding. Essentially this happens for two reasons (Prieto, 1973: p. 52). A so-called "mis-understanding" which occurs at the time that the message the sender seeks to transmit and the message that the receiver attributes to it are not one and the same. Provided the receiver does not fail to attribute a message to the signal, however, there is understanding of something, albeit different from what the sender intended. Another different failure occurs in the event that the receiver is unable to assign to the signal a particular message because there are two or more equally favored messages for the same circumstances. In this case there is "no understanding" because no message is allocated to the signal. In the mis-understanding the uncertainty disappears entirely because the receiver believes he has identified it, even if incorrectly, in the second case the ambiguity of the message conveyed by the sign does not disappear completely and uncertainty remains.

When failure of the semic act occurs, the main preoccupation that strikes the science teacher is to recognize the source of this failure so as to take any possible action to overcome it. Prieto (1973: p. 54) offers guidance to that effect by explaining that failure results not only from a false assessment of the circumstances in which the emitter's signal occurs, but also in believing that the receiver recognizes the circumstantial indication as being supposedly significant both in relation to the signal emitted and the circumstances that should favor the meaning of the signal. Thus the semic act fails because the message that the signal admits from the emitter's point of view, and imagined by him to be the most favored by the circumstantial indications, actually fails to be so from the receiver's perspective. Therefore, the false assessment by the emitter of the circumstantial indications, imagined as a fact known by the receiver at the moment of the semic act, 
does not really constitute a circumstantial indication. Only when the indication of the signal together with the circumstantial indications is meaningful to the receiver, can the latter realize that the received message belongs to the universe upon which the discourse is focused.

In particular, considering the instructional environment, the teacher's emission of possible signs with circumstantial indication role is a supportive element that promotes the understanding of signal messages during scientific communication. The state of understanding when achieved by the learner through the input of circumstantial indications tends to be significant, since deep, this is because they are autonomously appropriated by active reflection.

\section{Object of the Research}

Based on the overview of the theoretical semiotic elements outlined above, and adapting them to a reading of the teaching and learning situation, the role of the teacher is defined, as the emitter of knowledge. This role then, enables the student, the receiver of knowledge, to appropriate the scientific messages, assigning to them the intended scientific meanings. In the role of mediator of the emission of the signals of scientific messages, the former is the protagonist of this action. By making use of circumstantial indications, the teacher seeks to enhance the scientific significance of messages conveyed by the signals to the students. In order to adapt the terminology that will facilitate the proposed reading, henceforth signals are understood to be those sign constituents that shape and structure the primary plane of the discourse. They constitute the most obvious backbone of the discourse in which the teacher's main ideas appear. They are identified by the communicative elements transmitted by him immediately, directly, openly, explicitly and bluntly during the exchanges with the students.

In turn, concomitant with the signs, and on specific occasions, the teacher may make use of circumstantial indications to support the message communicated by the signals. In contrast, circumstantial indications are sign constituents transmitted indirectly and obliquely, and which are characterized by avoiding, an immediate direct, ready-made response or information from the teacher. Through the mediation of circumstantial indications, the teacher wants to stimulate the students' inference mechanisms so that they arrive at the information or answer, or idea or desired conclusion. With the responsibility to clarify, narrow down and illuminate the meaning of the signals, the circumstantial indication is intended to allow the meaning to take on or increase its relevance to students. As secondary signs in action, the circumstantial indications enter the discourse in a suggestive or covert way, seeking to support it in order to facilitate and supplement the messages of signals to enhance their meaning.

This paper has established and justified the subsidiary importance of circumstantial indications for the convergence of attention and understanding of the learner toward the meaning of signs through the reduction of ambiguity and the demarcation of the scientific universe of the discourse of the scientific concept being taught, this paper presents the results of a study that focuses on emis- 
sions of these types of signs by a teacher when in dialogic process with his students. The research focused on identifying the circumstantial indications and on the description of them as they appear in the discursive context.

In short, the problem that the article presents is to identify and characterize semiotic elements in a teacher's speech when a strategy of dialogic teaching is placed in the classroom. It will be shown that the use of the semiotic element based on the sign circumstantial indication is an attempt of the teacher to stimulate that the students reflect and overcome in an autonomous way the understanding of the scientific concepts. With this, teaching has the potential to become more meaningful to students than a traditional teaching conducted through information transmitted directly to the student.

This proposal rescues elements of the semiotics of Prieto (1973) and promotes an original didactic transposition of this framework for the teaching of sciences with educational objectives to improve students' understanding during the teaching of scientific contents.

\section{Methodology}

The nature of this research is interpretative qualitative, case study type, in that a regular class of a state university in Brazil in the Instrumentation discipline for the degree of Physics Teacher course was filmed and subsequently analyzed. The one year discipline consists mostly of experimental classes in which proposals for experiments in High School are presented and studied. During the threehour class the professor presented an experiment on the volumetric expansion of fluids. Ten students ( 7 males and 3 females) were divided into four groups of two or three. The objective of the experiment was to investigate whether the volumetric coefficient of expansion of water depended on the temperature and to determine its average value over the temperature range studied. The material used consisted of a test tube filled with water and sealed with a rubber stopper. The stopper was pierced by a transparent ballpoint pen tube and a thermometer to measure the temperature of the liquid. The water level, which due to the pressure of the stopper also partially filled the straw, was adjusted to appear at the point where it emerged from the stopper. This adjustment was made possible by means of a $5 \mathrm{ml}$ hypodermic syringe the needle of which passed through the stopper until it appeared within test tube. A volumetric scale covering the length of the straw using a strip of graph paper was used to measure changes in volume as the temperature of the liquid rose.

The experiment consisted of gradually heating the experimental apparatus in a container with previously heated water. The experiment was designed to obtain measurements of variations in volume of the expanded liquid and the corresponding temperatures at which this occurred. In addition to the experimental apparatus, the vessel with heated water, a sheet of millimetric graph paper to manually plot changes in volume with temperature, a calculator and a ruler were available, along with a $100 \mathrm{ml}$ beaker used to obtain the initial volume $\left(V_{o}\right)$ of liquid for determining the average coefficient of expansion, since the coefficient 
$\left[\gamma_{\text {average }}=\left(V_{o}\right)^{-1} \cdot(\Delta V / \Delta T)\right]$ is temperature dependent. The average value of the coefficient of expansion $\left(\gamma_{\text {average }}\right)$ is obtained from the average value of the volume change by the temperature variation $(\Delta V / \Delta T)$. Since the latter is equivalent to the curve slope at its respective temperature, its value is determined by averaging the tangents assessed on the constructed graph $(\operatorname{tg} \theta=\Delta V / \Delta T)$.

The class was primarily aimed at teaching laboratory instrumentation, for much of the teaching time students were involved in experimental practices. Therefore, the research concentrated its attention on those times when the teacher held collective discussions with the class. Video recording took place exclusively at those times, with the discussions with individual and isolated groups not being recorded, likewise those moments of activity when the students were performing the experiment, which occupied more than half the class time. The video material and the analyses carried out by the researcher were presented, explained and clarified to a group of eight independent researchers in order to reduce subjectivity and thus seek a more objective consensus on the interpretations of observations. Fundamentally, the protocol of analysis was devoted to differentiate the issuance by the teacher of signs of type signs of the type signs circumstantial indications.

In the class analyzed, the teaching methodology used by the teacher focused on the open issues of Gil \& Castro (1996), with adaptations of Laburú (2003), which involved discussions and questions sustained throughout the activity.

\section{Analysis and Discussion of Data}

In the particular teaching episode investigated during the discursive activity with the whole class, five circumstantial indications emitted by the teacher could be identified. The first occurred shortly after the teacher outlined the problem referring to evaluating whether the coefficient of volumetric expansion of water depends on temperature. In the event, before the students began the experimental activity and having perceived a level of difficulty in tackling the problem, the teacher, to help them overcome this difficulty, emitted a circumstantial indication that can be appreciated in the following excerpts from his utterance: "Pay attention, $P \mathrm{~m}$ going to give you a clue. Now look, the reasoning goes like this. Suppose, from the experimental data you have gathered, that you obtain a curved graph or perhaps a linear one like this (draws side by side a curved and linear graph), because anything is possible, we do not know what will occur, what type of graph. Observe that the abscissa and ordinate axes represent (respectively) the changes in volume and temperature that you will measure ..."; "Compare the graphs and the coefficients of volumetric expansion using this formula here (points to the $\gamma=\operatorname{tg} \theta \cdot\left(V_{o}\right)^{-1}$ written on the corner of the blackboard) ... Well ... I think now you have to give an interpretation as to whether the coefficient of expansion depends on the temperature or not'.

As noted, realizing the students' difficulty with the problem posed, the teacher begins by delivering some explicit comments. Linked to these direct signals, he emits a circumstantial indication given through the drawing of the two graphs 
with the intention of directing the students' appreciation. In this case, the graphical situation is intended to function as an indirect and parallel indication to the signal (problem and explicit statements) communicated in order to support it. Thus, this circumstantial indication sought to direct the decision of the students with respect to the problem of the dependence of the coefficient of expansion on temperature. In other words, the teacher offered the circumstantial indication concretized in graphical form. He trusted that the students would come to recognize, on their own, the circumstances that should provide the indication of the signal, which incorporates the message whether or not the coefficient of expansion depends on temperature.

The second circumstantial indication came in response to the previous indication; due to the fact the teacher had noticed the limited suggestive effect in completing the understanding of the students. This consisted of gestures used by the teacher following on from the graphical resources. More precisely, this statement occurred immediately following the teacher's utterance that sought to direct the attention of students to the message of the signal as follows: "Pay attention now to try to grasp what I want you to understand'. Without saying another word after this utterance, the teacher brushed the graph with the side of his hand and touched several parts of it with his fingers open and shut. He replaced these gestures with a ruler which struck the graph hard to make a noise, and in the same places where he had placed his hand. In this way, substituting and repeating the initial hand gestures.

Thus, at this point in time, dispensing for a few seconds with the oral resource in favor of gesticulations, the circumstantial indication emitted is performed by use of the hand that waves a ruler and also by the direct use of that instrument itself. With both media, the goal was to touch the side of the graphs drawn at various temperatures and, in this way, attract the concentration of class, including making use of the loud noise from beating the ruler on the frame. Then, the teacher sought indirectly, to indicate that the possibility that should be accepted, referring to the coefficient of expansion varying with temperature, should be the one constituted by the possibilities of the varying tangents $(\operatorname{tg} \theta=\Delta V / \Delta T$ that is proportional to $\gamma$ ). With both possibilities at stake at the indicating level, the teacher sought via his gestures to encourage the students to infer, from the universe of the discourse expounded, that the variations in the tangents are equivalent to the variations in the coefficient of expansion $(\Delta \operatorname{tg} \theta \sim \Delta \gamma)$, thus favoring, the message admitted by the signal. In this way, he intended the students to conclude that the message was, out of all messages admitted by the signal (the problem posed, the sum of the visualization of the formula $\gamma=\left(V_{o}\right)^{1} \cdot(\Delta V / \Delta T)$ and the statements related to it), that the circumstantial indications emitted by the gestures centered on the charts would most favor. With this second attempt, again the teacher aimed to direct the decision of the students with respect to how to solve the problem by providing clues or "hints" which, basically, by their nature, qualify as a gestured circumstantial indication, in this case, linked to a graphical object. 
The third circumstantial indication was characterized by the use of the resource of a second questioning following immediately on from a question posed by the learner. As has been known for some time, questions during lesson time have varied functions ranging from simple attention seeking by students, a check on what they are learning, or an important stimulus of thought, of critical thinking, or to control the discussions in the class room (Edwards \& Mercer, 1993: p. 46; Kawalkar \& Vijapurkar, 2013). In school life the learner learns and grows accustomed to the rituals inherent in this environment. One of these is that when the teacher, in his role as evaluator of the learning process, asks a second question immediately after a first question, it indicates that the previous answer was incorrect or is not the one desired by him (Edwards \& Mercer, 1993: p. 47).

Taking this into consideration, it was found that the teacher used the device mentioned at some points in the discursive activity, since certain students, realizing the unsatisfactory answer they or their colleagues had given, tried to rework the answer or the teacher's own question, following the indication of a second questioning from the teacher. Thus, in continuation of the earlier circumstantial indications and trying to check if students had grasped the problem that led to the previous circumstantial indications, the third circumstantial indication was identified as follows.

The teacher commenting on water's anomalous behavior in the range of $0^{\circ} \mathrm{C}$ to $4^{\circ} \mathrm{C}^{1}$, began with a question in order to determine whether students had understood that the behavior of the coefficient of expansion can be observed from the tangents of the graphs (volume by temperature) and whether they could apply this concept to the anomalous case of this temperature range, as follows: " And this chart now (of the water in the range of $0^{\circ} \mathrm{C}$ to $4^{\circ} \mathrm{C}$ drawn on the graph), how would you assess the expansion? That is, here, from $0^{\circ} \mathrm{C}$ to $4^{\circ} \mathrm{C}$ (pointing at the graph) does the volume of the water increase or decrease?" One student replied: "The volume increases ..., the coefficient changes because it is a curved graph, like the example in the previous graph".

The teacher, then knowing the answer to be incorrect, asks a second question: "The volume increases (repeating what the student said), you see that in this temperature range water has an anomalous behavior, as I said before, the expansion coefficient is negative. Look at this direction in which the temperature decreases and not this which $P m$ asking about. Here it goes from 4 to 0 degrees, the temperature decreasing. It's the same as a full PET bottle in freezer? The temperature there is also decreasing and what happens to the PET bottle?" One student replied: "It bursts". The teacher continues to probe: "So what happens when the temperature increases in this direction?" Another student then added: "The volume decreases, doesn't it, sir?"

As shown, the teacher's second question is noted to be a circumstantial indication meant to reinforce the meaning of the desired message of the original signal for the first question, that is, that the volume decreases with the increase ${ }^{1}$ The interval of the water temperature in which the coefficient of dilation of the water is negative. Consequently, the volume increases despite the decrease in temperature. 
in temperature.

Another occurrence of circumstantial indication of a similar nature to the previous one, was observed during the experimental activity. This happened when the teacher noticed in one of the groups that the equipment was leaking due to careless handling, because the stopper was not tight enough in the test tube. From this evidence the teacher asked, "Did you check if there was a leak? Did you push the stopper in tight?" Continuing to take measurements, a student from the group answered "yes (we checked)" while the others in the group stopped what they were doing and were looking at the teacher and the equipment. With the aim of encouraging the group to check this and realize the problem, because the answer was wrong and measurements were incorrect, the teacher again asked: "What is the volume reading at this temperature now?" One student from the group answered, "15.5 degrees". And the teacher continued the questioning: "If it is not leaking a few seconds from now, without doing anything, the volume should read what?" Two students in the group responded almost simultaneously: "The same (1 student)", "15.5 (student 2)”. The teacher, walked away from the group, saw that the students were conferring and that they had concluded that there was leakage and began to take new measurements once the equipment was sorted.

It can be seen that the questions subsequent to the first one functioned as circumstantial indications emitted by the teacher and related to the signal (first question). The teacher hopes that the message of these circumstantial indications would carry the meaning about the leak not having been checked. Therefore, the emission of additional questions to the first is a type of circumstantial indication that seek, by way of continuity, to assist in the revelation of the meaning of the original signal. As noted, the circumstantial indication provided by the subsequent questions is distinguished by its subjacent character to the signal. It works indirectly so that the message of the signal may be clarified and understood. The employment of such an indication acts in the sense of nudging the learner towards a moment of awareness that their first response are unsatisfactory and, therefore, aims to redirect his thinking to the message it is desired they should understand. Like any circumstantial indication, it operates in the sense of requiring an intellectual effort from the student themselves. It is opposed to those indexes issued directly, clearly, that is, to signs that could be typified by a curt reply from the teacher to the students merely to sort out the leaking equipment and repeat the experiment without the need for a greater reflective act.

Finally, the fifth circumstantial indication occurred in the following context. Having completed the discussions, the teacher asked the class what else was required to obtain the measurement of the coefficient of volumetric expansion, in accordance with the average graph tangent discussed $(\operatorname{tg} \theta=\Delta V / \Delta T)$ at the same time highlighting once again the formula $\left[\gamma=\left(V_{o}\right)^{1} \cdot(\Delta V / \Delta T)\right]$ to determine this coefficient. Many students, studying the formula, responded promptly that the initial volume of the water was required $\left(V_{o}\right)$. As a result, the 
teacher asked "How do we measure this value?" As the students remained silent, showing that they did not know the answer, the teacher instead of emitting another sign such as "use the beaker", thus simply handing them the answer to the problem, chose to complement the question (signal) by inquiring, "What item, only considering the items available on your desks (groups), could be used to measure the volume of water?" Some students indicated or answered pointing to the $100 \mathrm{ml}$ beaker, an item of equipment that had not yet been used by students and had not entered into the experimental procedures and discussions up to that point.

From this discursive interactive process, it was noted, together with the question posed (emission of the signal "how to measure this value $\left(V_{o}\right)$ ?"), the real, but also symbolic presence visibly shown by the beaker and indirectly prompted by further asking ("What item, only considering the items available on your desks (groups), could be used to measure the volume of water?"), among various items on the workbenches, constituted a manifestation of circumstantial indication in order to understand and respond to the question posed. The circumstantial indication that the idle beaker represents, among all the existing objects and within all the possible possibilities of being realized, is the most likely possibility of satisfying the transmitted signal ("to measure the initial volume $\left(V_{o}\right)$ "). The context of educational discourse has invested the beaker with the category of circumstantial indication. Thus it is through the beaker's symbolic role that it functions in helping to define the understanding of the signal message which, in this case, was about the desired solution. It should be noted, as a counterpoint, that if the teacher had just said "use the beaker" the emission of such an index would qualify as only a signal, the semic act of which being in the nature of an order would not have required further reflection by students, merely compliance. It should be noted also that the cylinder instrument, like any cultural object, has symbolic nature and communicative effectiveness (Laburú \& Silva, 2011a; Volli, 2012: p. 193), because the affordance presented in this object has its own morphology (matter, form, size, milliliter scale, suitable nozzle to pour liquids) which "invited" the intended use (Volli, 2012: p. 194).

Although it was not the object of study to investigate whether the circumstantial indications were successful, even though that was the intention of the teacher, the third, fourth and fifth circumstantial indications demonstrated that this happened. Their success can be explained because the teacher had judged correctly that students could likely benefit from circumstantial indications as supposedly significant to the transmitted signal. As an illustration, we have the fifth case, an example showing that the circumstantial indication in play, provided by the beaker, was successful. The same proved capable of being evaluated by students because they already knew its purpose and knew that it was the only instrument that had not been used in class, and therefore, strongly suggested that it might be there to measure something. So, the teacher's view that students would be able to appropriate the sign's message through the help of circumstantial indication proved to be correct since the indication fulfilled its role as a sup- 
plement and clarified the meaning of the message to them.

Finally, with regard to the classification of circumstantial indications, it was observed that they manifested themselves in different more predominant representational forms. According to Prain \& Waldrip (2006), the first presented in graphical form, the second in gestural mode and the third and fourth in the verbal mode. As for the fifth, it could be qualified as in the 3D representational mode (Prain \& Waldrip, 2006: p. 1844; Waldrip et al., 2010: p. 66; Laburú \& Silva, 2011a) i.e. that relies on objects or models by way of example.

\section{Conclusion}

This paper described and showed the occurrence of a particular type of sign with important implications for learning and that might be fostered by the teacher in the classroom during the discursive process. Called circumstantial indications, these signs accompany the messages of the signs in order to contextualize them and assist them in their meanings. Four indications were revealed in a class extract, displaying various representational forms of manifestation and teaching context that justify their attributions during the teacher's dialogue with his students. Because it was essentially a laboratory class, which occupied most of the students' time in experimental tasks, the investigation focused its attention on discussion moments. However, moments of private discussions between teacher-student or teacher-group in an isolated way in a traditional classroom are also potential moments of emission of circumstantial indications that can be investigated in future researches.

Certainly the context of emission of these signs is optimized and the more progressive and open educational approaches (Edward \& Mercer 1993, p. 2, 35) are present, insofar as the methodology used can provide and promote. In this sense, since the circumstantial indications concur with the aim of sharpening and enhancing the development of the meanings of the messages transmitted by the teacher's signs, their use cannot be dissociated from this type of educational approach, since it admits activities of active reflection on the part of learners themselves. Viewed in the context of a proposed sharing in the construction of knowledge and learning with meaning, it appears that the use of circumstantial indications supports the cognitive property of thought processes based on our abductive, deductive and inductive inferences. This is so, since the student is encouraged by them to search for a position on what was handed to him along with these forms of inference. Consequently, a higher prerogative is given to the student's autonomous construction and search for knowledge, compared to a passive reception of information and the provision of immediate and direct answers by the teacher.

As was quickly possible to show in the last example analyzed, the circumstantial indication succeeded in its provocation. Although the aim of examining the effect caused by circumstantial indications on learning exceeds the limits proposed by this study, nevertheless, this test is the main goal of the dialogue process. Thus, future research could focus on the consequences of the indica- 
tions for learning. And as mentioned in the introduction, in the case of circumstantial indications occurring almost subliminally to the student or, perhaps emitted by the teacher in an unplanned manner or without even being aware of having done them, it is possible to imagine that they might fail in their role of contributing to enlighten students' thinking. It is possible that its most unexpected effect acts in a misleading manner for the understanding of the meaning of the message, leading the learner to misunderstandings. Therefore, a more systematic research project in this direction would seem relevant.

In any event, we think that this study revealed an important semiotic element belonging to the discursive sphere which the teacher can make use of in dialogue with his students, provided he is committed to a more reflective teaching and learning experience with greater meaning.

\section{References}

Almeida, L. M. W., Pessoa da Silva, K. A., \& Vertuan, R. E. (2011). Sobre a categorização dos signos na semiótica peirceana em atividades de modelagem matemática. Revista Electrónica de Investigación en Educación em Ciencias, 6, 1-10.

Buyssens, E. (1974). Semiologia \& comunicação linguística (2a edição). São Paulo: Editora Cultrix Ltda.

Davis, N. T. (1993). Transição do objetivismo para o construtivismo na educação científica. International Journal of Science Education, 15, 627-636. https://doi.org/10.1080/0950069930150601

Duit, R. (2003). Conceptual Change: A Powerful Framework for Improving Science Teaching and Learning. International Journal of Science Education, 25, 671-688. https://doi.org/10.1080/09500690305016

Duval, R. (2004). Semiosis y pensamiento humano: Registros semióticos y aprendizajes intelectuales. Santiago de Cali, Colombia: Universidad del Vale, Instituto de Educación y Pedagogía.

Eco, H. (1985). O signo, Editorial Presença, LDA., Lisboa.

Eco, H. (2003). Tratado geral de semiótica. São Paulo: Estudos, Editora Perspectiva S. A.

Edwards, D., \& Mercer, N. (1993). Common Knowledge, the Development of Understanding in the Classroom, Routledge, London and New York.

Fidalgo, A. (1998). Semiótica: A lógica da comunicação. Covilhã, Portugual: Universidade da Beira Interior. http://www.bocc.ubi.pt

Fidalgo, A., \& GRADIM, A. (2005). Manual de semiótica, UBI, Portugal. http://www.ubi.pt

Freitas, M. T. A. (1995). Vygotsky \& Bakhtin. Psicologia e Educação: Um Intertexto (2nd ed.). São Paulo: Ática.

Gil, D., \& Castro, V. P. (1996). La Orientación de las Prácticas de Laboratorio Como Investigación: Un Ejemplo Ilustrativo. Enseñanza de las Ciencias, 14, 155-163.

Hubber, P., Tytler, R., \& Haslam, F. (2010). Teaching and Learning about Force with a Representational Focus: Pedagogy and Teacher Change. Research Science Education, 40, 5-28. https://doi.org/10.1007/s11165-009-9154-9

Jaipal, K. (2010). Meaning Making through Multiple Modalities in Biology Classroom: A Multimodal Semiotics Discourse Analysis. Science Education, 94, 48-72.

Kawalkar, A., \& Vijapurkar, J. (2013). Scaffolding Science Talk: The Role of Teachers' 
Questions in the Inquiry Classroom. International Journal of Science Education, 35, 2004-2027. https://doi.org/10.1080/09500693.2011.604684

Kendon, A. (2005). Gesture, Visible Action as Utterance. Cambridge: Cambridge University Press.

Kubli, F. (2005). Science Teaching as a Dialogue-Bakhtin, Vygotsky and Some Application in the Classroom. Science \& Education, 14, 501-534. https://doi.org/10.1007/s11191-004-8046-7

Laburú, C. E. (2003). Problemas Abertos e Seus Problemas no Laboratório de Física: Uma Alternativa Dialética que Passa Pelo Discursivo Multivocal e Univocal. Investigações em Ensino de Ciências, 8, 1-26. https://doi.org/10.1590/S1516-73132011000300013

Laburú, C. E., \& Silva, O. H. M. (2011). Multimodos e Múltiplas Representações: Fundamentos e Perspectivas Semióticas para a Aprendizagem de Conceitos Científicos. Investigações em Ensino de Ciências, 16, 7-33.

Laburú, C. E., \& Silva, O. H. M. (2011a). Laboratório Didático a Partir da Perspectiva da Multimodalidade Representacional. Ciência \& Educação, 17, 721-734.

Lemke, J. L. (2003). Teaching all the Languages of Science: Words, Symbols, Images, and Actions.

Manechine, S. R. S., \& Caldeira, A. M. A. (2010). Construção de Conceitos Matemáticos na Educação Básica Numa Abordagem Peirceana. Bolema, 23, 887-904.

Ogdan, C. K., \& Richards, I. A. (1989). The Meaning of Meaning. San Diego, CA: Harcourt Brace Jovanovich.

Oliveira, M. K. (1993). Vygotsky, Aprendizado e Desenvolvimento. Um Processo SócioHistórico. Série Pensamento e Ação no Magistério. São Paulo: Editora Scipione.

Prain, V., \& Waldrip, B. (2006). An Exploratory Study of Teachers' and Students' Use of Multi-Modal Representations of Concepts in Primary Science. International Journal of Science Education, 28, 1843-1886. https://doi.org/10.1080/09500690600718294

Prieto, L. J. (1973). Mensagens e Sinais. São Paulo: Editora Cultrix.

Putney, L. G. (2007). Discursive Practices as Cultural Resources: Formulating Identities for Individual and Collective in an Inclusive Classroom Setting. International Journal of Educational Research, 46, 129-140. https://doi.org/10.1016/j.ijer.2007.09.007

Radford, L. (2009). Why Do Gestures Matter? Sensuous Cognition and the Palpability of Mathematical Meanings. Educational Studies in Mathematics, 70, 97-109.

https://doi.org/10.1007/s10649-008-9127-3

Roth, W. M. (2001). Gestures: Their Role in Teaching and Learning. Review of Educational Research, 71, 365-392. https://doi.org/10.3102/00346543071003365

Santaella, L. (2005). Semiótica Aplicada. São Paulo: Thomson.

Volli, U. (2012). Manual de Semiótica (2nd ed., p. 347). São Paulo: Edições Loyoa.

Vygotsky, L. S. (2003). Pensamento e Linguagem (2nd ed., p. 194). São Paulo: Martins Fontes.

Waldrip, B., Prain, V., \& Carolan, J. (2010). Using Multi-Modal Representations to Improve Learning in Junior Secondary Science. Research Science Education, 40, 65-80. https://doi.org/10.1007/s11165-009-9157-6

Wartha, E. J., \& Rezende, D. B. (2011). Os Níveis de Representação no Ensino de Química e as Categorias da Semiótica de Peirce. Investigações em Ensino de Ciências, 16, 275290. 
Submit or recommend next manuscript to SCIRP and we will provide best service for you:

Accepting pre-submission inquiries through Email, Facebook, LinkedIn, Twitter, etc. A wide selection of journals (inclusive of 9 subjects, more than 200 journals)

Providing 24-hour high-quality service

User-friendly online submission system

Fair and swift peer-review system

Efficient typesetting and proofreading procedure

Display of the result of downloads and visits, as well as the number of cited articles Maximum dissemination of your research work

Submit your manuscript at: http://papersubmission.scirp.org/

Or contact ce@scirp.org 